\title{
Individual signatures in the vocal repertoire of the endangered Mediterranean monk seal: new perspectives for population monitoring
}

\author{
Isabelle Charrier ${ }^{1, *}$, Schédir Marchesseau ${ }^{1}$, Panagiotis Dendrinos $^{2}$, Eleni Tounta ${ }^{2}$, \\ Alexandros A. Karamanlidis ${ }^{2}$
}

${ }^{1}$ Université Paris-Saclay, Université Paris-Sud, CNRS, UMR 9197, Institut des Neurosciences Paris-Saclay, 91405 Orsay, France

${ }^{2}$ MOm/Hellenic Society for the Study and Protection of the Monk Seal, Solomou Str. 18, 10682 Athens, Greece

\begin{abstract}
The Mediterranean monk seal Monachus monachus is considered Endangered by the IUCN, and is the most endangered pinniped in the world. Increasing our knowledge of this species is crucial in order to further our understanding of its social behaviour, but also to develop new methods to monitor and protect it. In many species, acoustic communication plays a major role in social interactions, and vocal signals convey important information about the emitter; understanding the diverse information encoded in vocalizations is helpful in wildlife monitoring. In the present study, we used passive, audio-video surveys to describe the aerial vocal repertoire of the Mediterranean monk seal during the pupping season. An exhaustive analysis was performed on the different call types, and individual vocal signatures were investigated. A total of 5 call types were identified: bark, chirp, grunt, short scream and scream, with bark and scream being the 2 main call types. A discriminant function analysis based on 10 acoustic variables revealed that all call types except grunts can be correctly classified, with an average rate of $86.7 \%$. Furthermore, the individual vocal signature investigated in barks and screams revealed that both call types are individually specific, showing average correct classification rates of 54.2 and $66.1 \%$ respectively. Based on these findings, future research should focus on collecting new recordings from wellidentified seals to develop a new passive acoustic monitoring system based on individual identification. This system will enable the evaluation of annual pup production and thus provide essential information on the conservation status of the Mediterranean monk seal in Greece.
\end{abstract}

KEY WORDS: Acoustic monitoring - Eastern Mediterranean Sea - Monachus monachus · Vocal repertoire $\cdot$ Individual signature

\section{INTRODUCTION}

The Mediterranean monk seal Monachus monachus is the sole representative of the genus Monachus (Scheel et al. 2014). Following decades of teetering on the brink of extinction, the species has recently been showing encouraging signs of population recovery in the main areas of its distribution (Karamanlidis et al. 2016) and is now classified by the

\footnotetext{
${ }^{*}$ Corresponding author: isabelle.charrier@u-psud.fr
}

International Union for Conservation of Nature (IUCN) as Endangered (Karamanlidis \& Dendrinos 2015). This new conservation reality poses new challenges for the monitoring, management and conservation of the Mediterranean monk seal, especially in a rapidly changing, human-dominated environment such as the eastern Mediterranean Sea, which is the main distribution area of the species (Karamanlidis et al. 2016). Therefore, any information on the behaviour

(C) The authors 2017. Open Access under Creative Commons by Attribution Licence. Use, distribution and reproduction are unrestricted. Authors and original publication must be credited. 
of this elusive and poorly understood species will not only help in understanding its biology, but also aid in developing new methods to monitor and promote its effective management and conservation.

Acoustic communication plays a fundamental role in the survival and reproduction of many species. Acoustic signals are involved in the recognition of individuals, kin, species, in mate selection, parental care and the regulation of emotional expression (Bradbury \& Vehrencamp 1998). Acoustic communication is well developed in marine mammals, as sound is the most efficient sensory signal for longrange communication in air and under water (Tyack 1999). Like most marine mammals, pinnipeds (i.e. true seals, fur seals, sea lions and walruses) use vocalizations to organize their social activities and to serve vital biological functions, such as territorial defence, mate selection, attendance on young and protection of conspecifics (Insley et al. 2003). Acoustic signals can convey different types of information about the emitter: its species, group and individual identity, age, gender, physiological and emotional state, body condition and social status. Decrypting the different types of information encoded in vocal signals can be very useful in developing monitoring methods in order to detect the presence of a target species, evaluate the number of individuals and estimate population structure (Mellinger et al. 2007, Blumstein et al. 2011). In addition, as some acoustic features are linked to phenotype (Titze 1994) or stress levels (Briefer et al. 2015), information on the body condition and/or emotional state of a specific individual can also be extracted.

In the last decade, the use of passive acoustics has been widespread in cetacean (Watkins et al. 2000, Charif et al. 2001, Nieukirk et al. 2004, Širović et al. 2004, Moore et al. 2006) and pinniped monitoring (Thomas \& DeMaster 1982, Van Parijs \& Clark 2006, Klinck et al. 2010, Van Opzeeland et al. 2010, Mouy et al. 2012, Rogers et al. 2013). The methodology has shown a high potential in surveying populations and migration movements in many areas, especially those where visual observations are rare and extremely difficult (i.e. polar areas and remote, inaccessible islands). Assessing the species-specific vocal repertoire is very important in estimating temporal changes in the presence and abundance of species/ individuals inhabiting a study area. Simple information, such as assessing species identity can be a difficult task as the vocal repertoires of some species are totally unknown or only partially described (e.g. some baleen whales in cetaceans; aerial and underwater repertoire of Mediterranean monk seals and underwater vocalizations of Hawaiian monk seals Neomonachus schauinslandi). It is therefore of utmost importance for conservation to combine acoustic data with visual observations and to perform focal studies on the vocal behaviour of target species for which the vocal repertoire is still poorly known. Assessing the vocal repertoire of a given species is the initial step in setting up an acoustic monitoring scheme with the aim of using vocal activity as a method to survey populations over the long term. To accomplish this, it is crucial to assess individual vocal signatures using focal recordings. In pinnipeds, individual vocal signatures have been mainly studied using playback experiments, for aerial calls between mothers and pups (Charrier et al. 2002, 2003, Pitcher et al. 2012). In these studies, the individual vocal signatures used by animals have been decrypted. However, a less complex task aiming to classify individuals using their vocalizations can be done by performing acoustic statistical analyses without testing animals. Such 'passive' individual classifications have been performed on many pinnipeds, with both aerial and underwater calls of mother-pup pairs and males (Insley et al. 2003, Collins et al. 2005, 2006, Charrier \& Harcourt 2006, Khan et al. 2006, Van Parijs \& Clark 2006, Risch et al. 2007, Gwilliam et al. 2008, Van Opzeeland et al. 2009, Charrier et al. 2010, Trimble \& Charrier 2011, Sauvé et al. 2015).

In the present study, we used passive acoustics to record and describe the aerial vocal repertoire of the Mediterranean monk seal around Greece. By assessing vocalizations and their context of production through video recordings, we defined the vocal repertoire of the Mediterranean monk seal and identified the main acoustic characteristics of each call type produced by the species. In a second step, we performed a more detailed analysis of the 2 main call types produced by the seals, and investigated the presence of individual vocal signatures in these vocalizations. The results of the study shed new light on the vocal behaviour of the Mediterranean monk seal and are being discussed in view of the necessity to develop new monitoring methodologies for the effective conservation of this species.

\section{MATERIALS AND METHODS}

\section{Study location and animals}

Mediterranean monk seals were studied at 2 of their most important pupping sites on the island of Evoia $\left(38^{\circ} 30^{\prime} \mathrm{N}, 24^{\circ} 00^{\prime} \mathrm{E}\right)$, Greece, during the 2013 
pupping season (i.e. August 2013 to January 2014). The Mediterranean monk seal colony at the island of Evoia has only recently been discovered, and consists of individuals of all age and sex classes that occupy the area year round (Karamanlidis et al. 2015). Based on the external morphology (Samaranch \& González 2000), a minimum of 10 subadult and adult individuals ( 5 female, 5 male) and 6 pups have been individually identified (Karamanlidis et al. 2015).

\section{Recording procedure}

Three high definition trail cameras with audio recording (Ltl Acorn 6210MC HD Trail Camera, invisible infrared, $12 \mathrm{MP}$ resolution, audio: $\mathrm{FS}=32 \mathrm{kHz}$ ) were set up: 2 cameras were installed at cave EVI 1 and 1 camera in cave EVI 19 (see Supplementary Video at www.int-res.com/articles/suppl/n032p459_supp/). The audio-video recordings were triggered by the animals' movements and lasted for $1 \mathrm{~min}$. The cameras used non-visible infrared technology and were therefore particularly suitable for monitoring and recording animals in complete darkness without interfering with individual behaviours.

\section{Vocal repertoire and acoustic analyses}

Each vocalization was extracted from the video files and correlated with the behavioural context of the vocalization observed in the video. Whenever possible, vocalizations were assigned to uniquely identified individuals. Individual identification was occasionally not possible (i.e. animal out of camera focus, low quality recording, lack of distinctive features to distinguish an individual); in these cases, and if 2 successive recordings were more than $15 \mathrm{~min}$ apart, they were not considered to belong to a previously identified individual and were assigned to a 'new' individual. This highly conservative method has led to an over-estimation of individuals, but also has avoided the incorrect identification of individuals.

To describe the vocal repertoire of the Mediterranean monk seal we defined different vocal types by inspecting spectrograms. The analysis only included sounds produced by the vocal tract; thus, sounds like snorts (i.e. exhalation of air from the nostrils) were not analysed. We used the same call types previously described by Muñoz et al. (2011) for wild and captive Mediterranean monk seals, and we identified new call types not described previously.
Acoustic analyses were performed only on goodquality vocalizations; we selected calls with low background noise and no overlap with other vocalizing animals. In general, this meant that selected calls showed a signal-to-noise ratio (SNR) greater than $30 \mathrm{~dB}$, information from the spectrogram and its amplitude scale. Using Avisoft SAS Lab Pro v.5.207 (R. Specht, Avisoft Bioacoustics) we measured the following 11 variables: total duration of the call (DUR; $\mathrm{ms})$, frequency value of the $1^{\text {st }}$ peak $\left(F_{\max 1 ;} \mathrm{Hz}\right)$, fundamental frequency $\left(\mathrm{F}_{\mathrm{o}} ; \mathrm{Hz}\right)$, frequency excursion $\left(F_{\text {exci }} \mathrm{Hz}\right)$, quartiles $(\mathrm{Q} 25, \mathrm{Q} 50$ and Q75; Hz), energy below $1500 \mathrm{~Hz}$ (E1500; \%), and lastly the frequency bandwidth within which the energy falls within $12 \mathrm{~dB}$ of the first peak (BDW; Hz), which we calculated as the difference between its maximum and minimum values $\left(\mathrm{BDW}_{\min }, \mathrm{BDW}_{\max } \mathrm{Hz}\right)$.

The total duration of a call was measured on an oscillogram (cursor precision: $1 \mathrm{~ms}$ ). $F_{\text {exc }}$ was assessed by calculating the difference between the minimum and maximum frequencies measured on the first visible harmonic from the spectrogram (Hamming window, FFT size $=1024 \mathrm{pts}$, cursor precision $=$ $20 \mathrm{~Hz}$ ). The averaged value of $F_{o}$ and all the spectral variables $\left(\mathrm{F}_{\max 1}, \mathrm{Q} 25, \mathrm{Q} 50, \mathrm{Q75}, \mathrm{E} 1500, \mathrm{BDW}_{\min }\right.$ $\mathrm{BDW}_{\max }$ ) were assessed from the average energy spectrum (Hamming window, frequency resolution = 1 to $2 \mathrm{~Hz}$, depending on the call duration) computed on the entire length of the call.

\section{Statistical analysis}

Vocalizations were categorized when possible according to their general structure and the behavioural context during which they were produced. We computed a 1-way analysis of variance (ANOVA) or a Welch ANOVA (for unequal variances tested with Bartlett tests) on each acoustic variable to assess significant differences among call types. Our call-type classification was further investigated using a discriminant function analysis (DFA), a classification method primarily used to predict group membership from a set of continuous variables. We also performed a cross-validation DFA, using the cross-validation leave-one-out method to assess the reliability of the DFA results.

We examined individuality levels using 3 different analyses in barks and screams only. Analysis of individuality levels could not be performed on chirps and short screams because of the small sample size (i.e. $<5$ calls for each individual; chirps: 11 calls from 4 individuals, short screams: 60 calls 
from 28 individuals). Initially, we calculated the potential for individual coding (PIC) for each acoustic parameter. This was assessed by calculating the $\mathrm{CV}_{\mathrm{b}} / \mathrm{CV}_{\mathrm{i}}$ ratio, where $\mathrm{CV}_{\mathrm{b}}$ is the betweenindividual coefficient of variation and $C_{i}$ is the average of all within-individual CVs (Robisson et al. 1993). All coefficients of variation were calculated using the correction for small sample sizes: $\mathrm{CV}=(\mathrm{SD} / \mathrm{x})[1+(1 / 4 n)]$, where SD is standard deviation, $x$ is the mean of the given individual and $n$ is the number of calls for a given individual (Sokal \& Rohlf 1981). For a given acoustic variable, a PIC value $>1$ indicates that this variable is individual-specific, because the intra-individual variability is smaller than the inter-individual variability (Robisson et al. 1993). Then we computed a 1-way ANOVA or Welch ANOVA for each acoustic variable to assess significant differences among individuals. Finally, we performed a DFA using a maximum of 5 acoustic variables, because the smallest sample size for individuals was 5 calls, and the number of predictors (i.e. acoustic variables) should not exceed the smallest sample size (Büyüköztürk 2008). We therefore selected the acoustic variables showing both the highest PIC values (i.e. the most individualized variables) and significant differences among individuals (i.e. ANOVA with significant results). In this way, we optimised the discrimination among individuals. We also computed a crossvalidation leave-one-out for the DFA to assess the correct classification rate per individual.

All statistical analyses were performed using R Studio v.3.1.0 (R Development Core Team 2014) using the 'mass' and 'RcmdrPlugin.NMBU' packages.

\section{RESULTS}

\section{Vocal repertoire and call analyses}

During the study period, 1593 1-min video files were collected, but only 353 files contained animals vocalizing. A total of 331 good-quality vocalizations were extracted; these calls were produced by a maximum of 66 individuals: 10 well-identified seals (i.e. 2 adult males, 4 adult females, 2 juvenile males, 1 female and 1 male pup), 22 unidentified adult females, 6 unidentified juvenile males and 28 unidentifiable individuals. Based on visual inspection of the spectrograms and social context, vocalizations were divided into 5 call types: bark, scream, short scream, chirp and grunt (Fig. 1, and see Supplementary

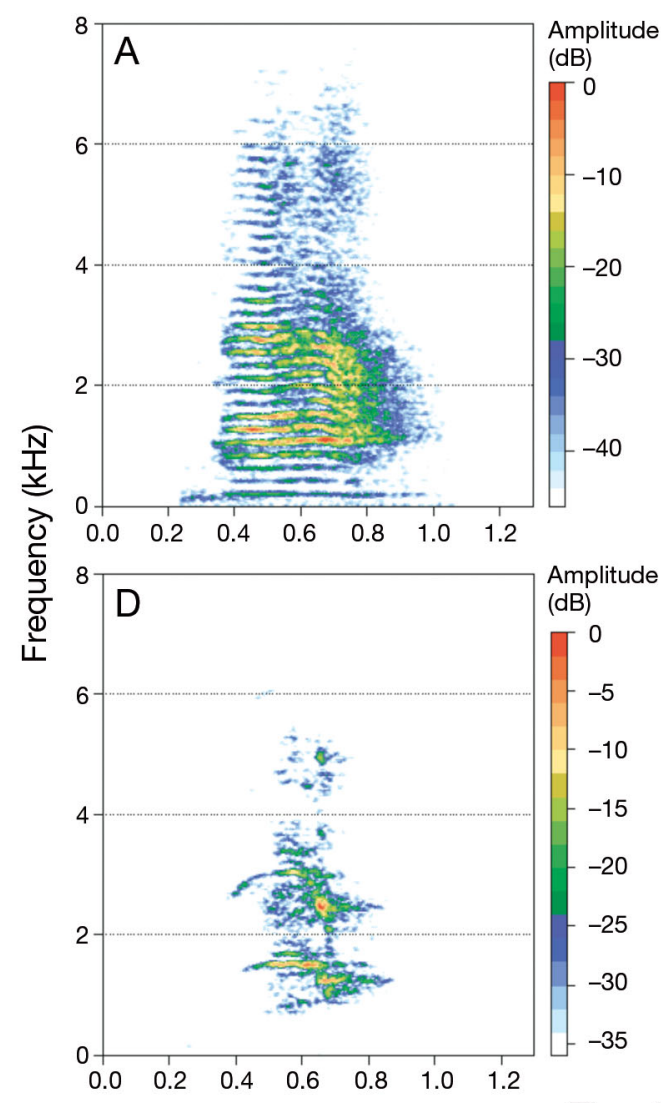

Time (s)
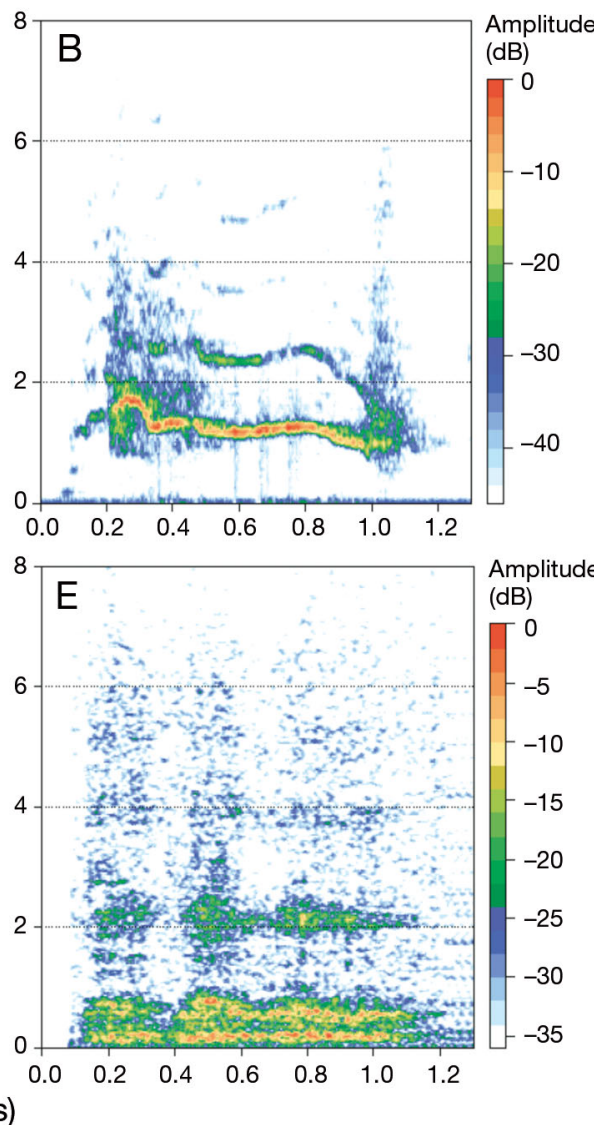

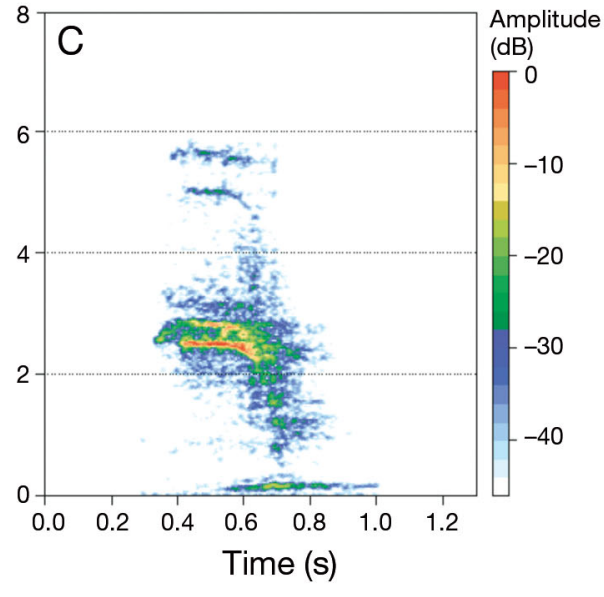

Fig. 1. Aerial call types produced by Mediterranean monk seals Monachus monachus: (A) bark, (B) scream, (C) short scream, (D) chirp, and (E) grunt. Spectrogram parameters: Hamming window, FFT window size: 1024 pts, $90 \%$ overlap. Figure constructed using Seewave (Sueur et al. 2008) 
Video). Acoustic analysis was performed on 4 call types (bark, scream, short scream and chirp), as grunt sample size was too small $(\mathrm{n}=14)$. Table 1 provides the results of the univariate analyses performed on the 10 acoustic variables and the post hoc GamesHowell tests.

Mediterranean monk seal barks (Fig. 1A, Table 1) are tonal calls composed of a fundamental frequency and its harmonics series, and show an inverted Ushaped frequency modulation pattern. Barks are produced by all individuals during agonistic interactions, but also during affiliative interactions, such as mother-pup vocal exchanges. Barks are relatively short (DUR: $350 \pm 235 \mathrm{~ms}$ ) with lower frequencies than other call types (percentage of energy below $1500 \mathrm{~Hz}, \mathrm{E} 1500: 44.1 \pm 10 \%$ ) and show a weak frequency modulation pattern $\left(\mathrm{F}_{\text {exc }}: 74 \pm 32 \mathrm{~Hz}\right)$. The frequency bandwidth is quite large (BDW: $1636 \pm$ $993 \mathrm{~Hz})$, starting at a very low frequency $\left(\mathrm{BDW}_{\min }\right.$ : $356 \pm 366 \mathrm{~Hz}$ ), indicating that energy is widespread among several harmonics around the frequency peak ( $\left.\mathrm{F}_{\max 1}: 843 \pm 496 \mathrm{~Hz}\right)$.

Compared to barks, screams (Fig. 1B, Table 1) are long (DUR: $833 \pm 460 \mathrm{~ms}$ ) and high-pitched vocalizations (E1500: $12.5 \pm 10.8 \%$ ) that are produced during agonistic interactions between adults and/or juveniles. The frequency modulation pattern in screams fluctuates highly both within and between individuals $\left(\mathrm{F}_{\text {exc }}: 488 \pm 276 \mathrm{~Hz}\right.$ ), while most of the energy (BDW: $417 \pm 392 \mathrm{~Hz}, \mathrm{BDW}_{\min }$ : $1895 \pm 470$ ) is concentrated around the first energy peak $\left(\mathrm{F}_{\max 1}\right.$ : $2053 \pm 437 \mathrm{~Hz}$ ).

The short screams (Fig. 1C, Table 1) are produced in the same behavioural context as screams (i.e. during agonistic interactions), and are also high-pitched vocalizations (E1500: $16.9 \pm 12 \%, \mathrm{~F}_{\max 1}: 1876 \pm$ $352 \mathrm{~Hz}$ ). Most of the energy of the short screams is concentrated around the first energy peak (BDW: 403 $\pm 541 \mathrm{~Hz}, \mathrm{BDW}_{\min }: 1728 \pm 407 \mathrm{~Hz}$ ). The main difference between short screams and screams is their shorter duration (DUR: $432 \pm 156 \mathrm{~ms}$ ).

Chirps (Fig. 1D, Table 1) are short (DUR: $367 \pm$ $52 \mathrm{~ms}$ ), high-pitched vocalizations (E1500: $6.4 \pm$ $6.6 \%, \mathrm{~F}_{\max 1}: 2422 \pm 316 \mathrm{~Hz}$ ), with most of the energy concentrated on the first visible harmonic (BDW: 579 $\pm 426 \mathrm{~Hz}_{1} \mathrm{BDW}_{\min }: 2291 \pm 327 \mathrm{~Hz}$ ) and a typical and consistent frequency modulation pattern $\left(\mathrm{F}_{\text {exc }}: 275 \pm\right.$ $119 \mathrm{~Hz}$ ). The context in which chirps are produced varies greatly, as they are produced during agonistic interactions between adults, as well as during mother-pup interactions. Chirps are produced only by adults, and quite rarely: we collected only 11 chirps from 4 different individuals.

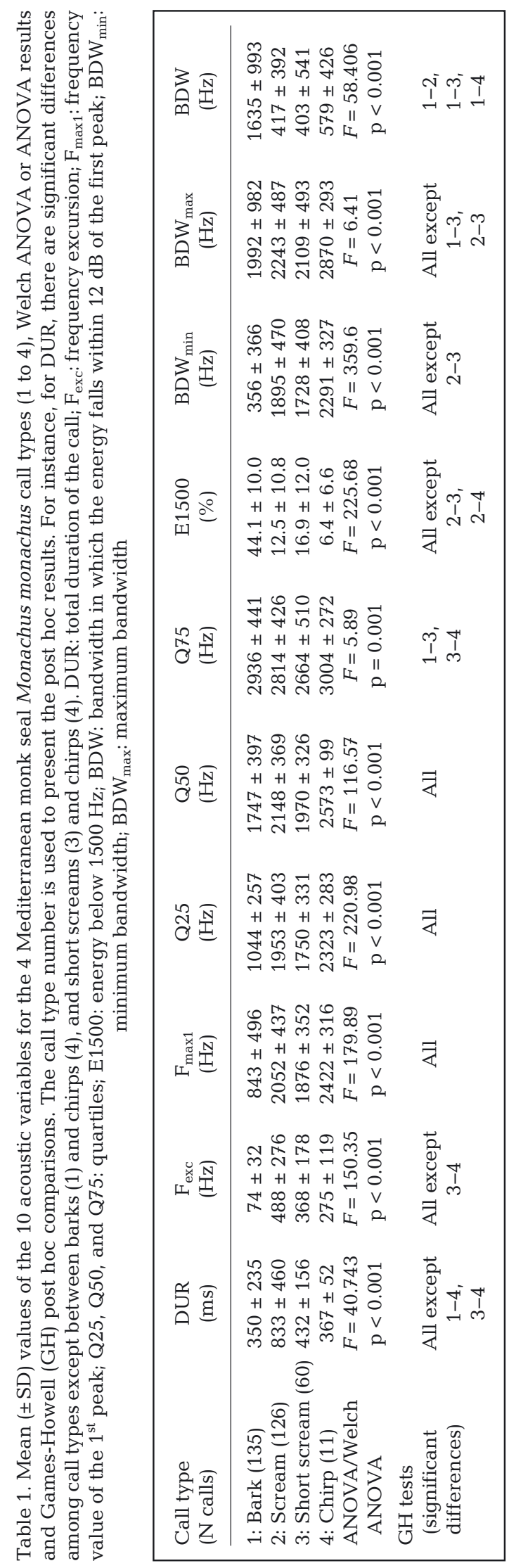




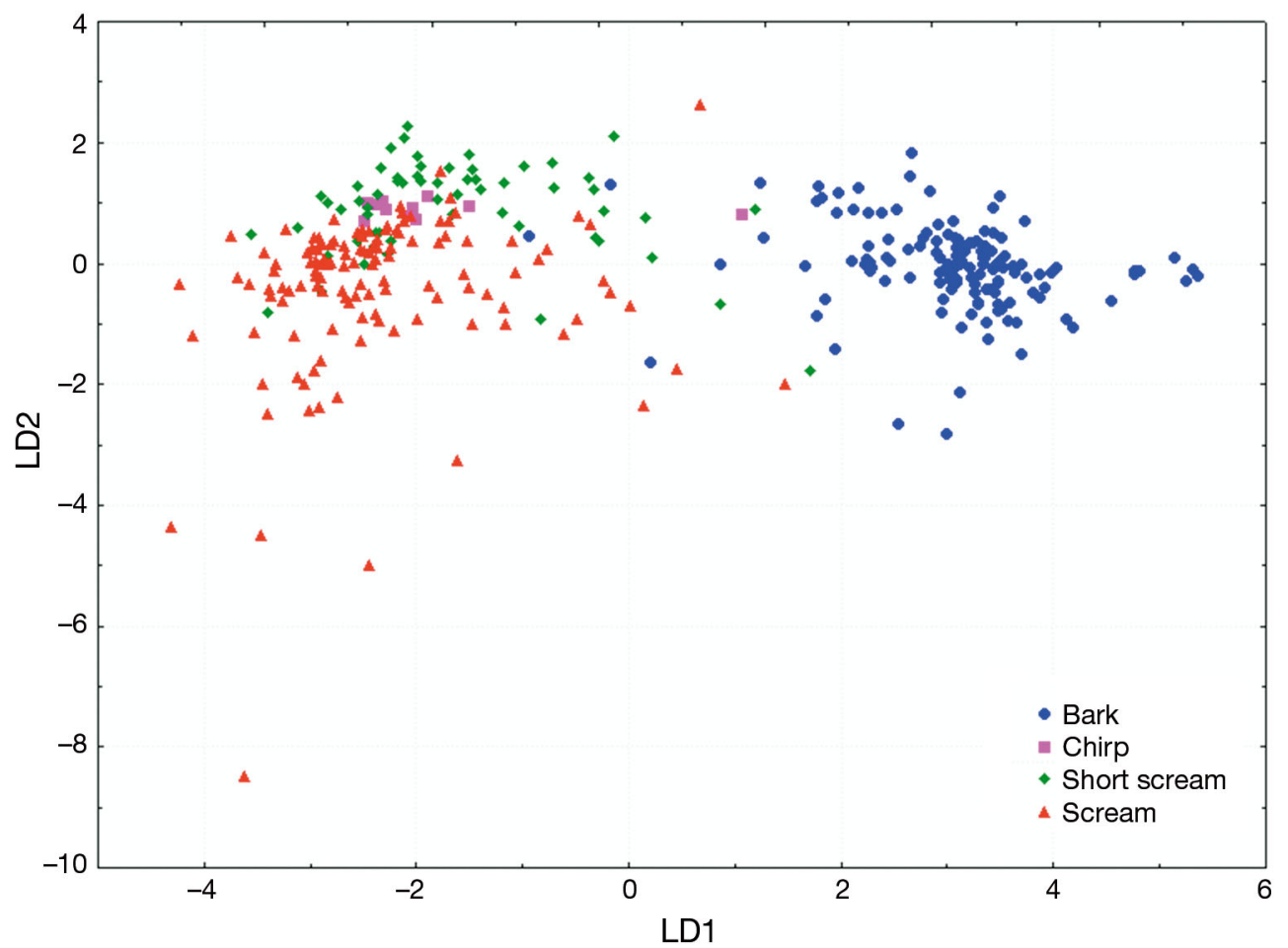

Fig. 2. Scatterplot of LD1 and LD2 of the discriminant function analysis (DFA) performed on 10 acoustic variables measured on 4 different call types of the Mediterranean monk seal Monachus monachus

The DFA extracted 3 roots that accounted for 94.7, 3.6 and $1.7 \%$ of the total variance respectively. Three acoustic variables, $\mathrm{BDW}_{\min }, \mathrm{Q} 50$ and $\mathrm{E} 1500$ were the variables contributing the most to the variation (LD1), and DUR to a lesser extent (LD2). Basically, spectral features and duration were the main characteristics allowing a clear differentiation among call types (Fig. 2). Vocalizations were classified to the correct call type at an average rate of $86.7 \%$ (Table 2, Fig. 2). Barks and screams showed the highest correct classification rates, 97.8 and $88.1 \%$ respectively, followed by short screams (64.4\%) and chirps (54.5\%). All average classification rates were higher than expected by chance (Table 2). In the cross-validated DFA, the average correct classification rate was $84.9 \%$, with rates ranging from $36.4 \%$ (chirps) to $97.8 \%$ (barks), which was higher than expected by chance (Table 2).

\section{Individual stereotypy levels in barks and screams}

A total of 72 barks from 10 different individuals (5 to 11 calls ind.$^{-1}$ ) were analyzed. Coefficients of variation within an individual $\left(\mathrm{CV}_{\text {intra }}\right)$ were lower than coefficients of variation between individuals $\left(\mathrm{CV}_{\text {inter }}\right)$ for all acoustic variables measured, except $\mathrm{F}_{\max 1}$ and BDW, resulting in PIC values $>1$ (Table 3). Therefore, these variables may allow individual discrimination based on barks. However, the results of the ANOVA/Welch ANOVA showed that some acoustic variables $\left(F_{o}, F_{\text {exc }}, F_{\max 1}, B D W\right.$; see Table 3) were not significantly different among individuals, and therefore these features were not included in the DFA. Five acoustic variables (i.e. DUR, Q25, Q50, Q75, BDW $\min$ ) were selected to compute the DFA.

The DFA extracted 5 roots, with the first 3 roots accounting for $48.1,32.3$ and $13.4 \%$ of the total variance respectively. The variables contributing the most to the variation were DUR and $\mathrm{BDW}_{\min }$ (LD1), and to a lesser extent the different energy quartiles. Vocalizations were classified to the correct individual

Table 2. Classification matrix obtained with the cross-validated discriminate function analysis (DFA; leave-one-out method) on the 4 call types of Mediterranean monk seals Monachus monachus. Numbers in bold indicate the number of calls assigned to the correct call type

\begin{tabular}{|lcccc|}
\hline Predicted & Bark & Chirp & Short scream & Scream \\
\hline Bark & $\mathbf{1 3 2}$ & 1 & 3 & 2 \\
Chirp & 0 & $\mathbf{4}$ & 0 & 7 \\
Short scream & 2 & 0 & $\mathbf{3 8}$ & 10 \\
Scream & 1 & 6 & 18 & $\mathbf{1 0 7}$ \\
Total & 135 & 11 & 59 & 126 \\
\% Correct & 97.8 & 36.4 & 64.4 & 84.9 \\
\% Chance & 40.79 & 3.32 & 17.8 & 38.06 \\
\hline
\end{tabular}


Table 3. Potential for individual coding (PIC) values for each acoustic variable measured on Mediterranean monk seal Monachus monachus barks ( 72 calls from 10 individuals) and screams ( 71 calls from 8 individuals), and differences among individuals $(F-$ and p-values are for ANOVA or Welch ANOVA tests). See Table 1 for acoustic variable definitions; $F_{\mathrm{o}}$ : fundamental frequency

\begin{tabular}{|c|c|c|c|c|c|c|c|c|c|c|c|}
\hline Variables & DUR & $\mathrm{F}_{\mathrm{o}}$ & $\mathrm{F}_{\text {exc }}$ & $\mathrm{F}_{\max 1}$ & Q25 & Q50 & Q75 & E1500 & BDW & $\mathrm{BDW}_{\min }$ & $\mathrm{BDW}_{\max }$ \\
\hline \multicolumn{12}{|l|}{ Barks } \\
\hline $\mathrm{PIC}$ & 2.01 & 1.06 & 1.06 & 0.96 & 1.2 & 1.27 & 1.17 & 1.1 & 0.99 & 1.71 & 1.06 \\
\hline$F$-value & 6.19 & 1.54 & 1.15 & 1.57 & 3.01 & 3.79 & 4.57 & 2.96 & 1.99 & 22.18 & 3.05 \\
\hline p-value & $<0.001$ & 0.197 & 0.343 & 0.143 & $<0.005$ & $<0.005$ & $<0.005$ & 0.006 & 0.056 & $<0.001$ & $<0.005$ \\
\hline \multicolumn{12}{|l|}{ Screams } \\
\hline PIC & 1.31 & - & 1.21 & 1.86 & 2.23 & 1.91 & 1.17 & 1.57 & 1.62 & 1.85 & 1.42 \\
\hline$F$-value & 2 & - & 0.42 & 26.3 & 47.37 & 35.18 & 5.23 & 9.28 & 2.13 & 33.43 & 28.1 \\
\hline p-value & 0.1007 & - & 0.886 & $<0.001$ & $<0.001$ & $<0.001$ & $<0.005$ & $<0.001$ & 0.087 & $<0.001$ & $<0.001$ \\
\hline
\end{tabular}

at an average rate of $54.2 \%$ (range: 20 to $80 \%$ ) (Table 4). All classification rates were higher than expected by chance. In the cross-validated DFA, the average correct classification rate was $34.7 \%$ (range: 0 to $75 \%$ ). All classification rates were higher than chance, except for 3 individuals $(0 \%$ classification rates). Nine of the 10 individuals selected for the bark analysis were from cave 2 and only one from cave 1. The classification rates for the 9 individuals in the same cave show that we can discriminate them, and thus the difference found among individuals cannot be explained by a difference in the acoustic properties of the caves.

A total of 71 screams from 8 individuals were analysed (5 to 15 calls ind. ${ }^{-1}$ ). $\mathrm{CV}_{\text {intra }}$ were lower than $\mathrm{CV}_{\text {inter }}$ for all acoustic variables measured, resulting in PIC values $>1$ (Table 3 ). Therefore, these variables may allow individual discrimination based on screams. However, the results of the ANOVA/ Welch ANOVA indicated that some acoustic variables (i.e. DUR, $F_{\text {exc }}$ BDW; see Table 3) were not significantly different among individuals, and thus these features were not included in the DFA; only $\mathrm{F}_{\max 1}, \mathrm{Q} 25, \mathrm{Q} 50, \mathrm{BDW}_{\min }$ and $\mathrm{BDW}_{\max }$ were selected for the DFA.

The DFA extracted 5 roots, with the first 3 contributing $79.6,16.9$ and $2.3 \%$ of the total variance respectively. The variables contributing the most to the variation were $\mathrm{BDW}_{\text {min }}$ and Q25 (LD1) and to a lesser extent Q50 (LD2). Vocalizations were classified to the correct individual with an average rate of $66.2 \%$ (range: 10 to $100 \%$ ) (Table 4). All classification rates were higher than expected by chance, except for 1 individual (10 vs. $14 \%$ ). In the cross-validated DFA the average correct classification rate was $53.5 \%$ (range: 0 to $86.7 \%$ ). All classification

Table 4. Average percentage of calls correctly classified for various phocid species (pup, mother and male calls)

\begin{tabular}{|llll|}
\hline Phocid species & Call type & $\begin{array}{l}\text { Correct classifi- } \\
\text { cation rates }\end{array}$ & Reference \\
\hline Halochoerus grypus & Pup calls & 32 & McCulloch et al. (1999) \\
Hydrurga leptonyx & Male trills & $58^{\text {a }}-77^{\text {a }}$ & Rogers \& Cato (2002) \\
Leptonychotes weddellii & Pup calls & 29 & Collins et al. (2006) \\
& Mother calls & 56 & Collins et al. (2005) \\
Mirounga angustirostris & Pup call & $64^{\text {a }}$ & Insley (1992) \\
& Mother calls & $54^{\text {a }}$ & Insley (1992) \\
Monachus monachus & Male threat call & 61.3 & Casey et al. (2015) \\
& Barks (pups + adults) & $54.2^{\text {a } / 34.7}$ & This study \\
Neomonachus schauinslandi & Screams (adults) & $66.2^{\mathrm{a}} / 53.5$ & This study \\
Phoca groenlandica & Pup calls & 14 & Job et al. (1995) \\
Phoca vitulina & Pup calls & $43^{\mathrm{b}}$ & Van Opzeeland \& Van Parijs (2004) \\
aDiscriminant function analysis (DFA) results without cross-validation & Khan et al. (2006), Sauvé et al. (2015) \\
besults with classification and regression tree (CART) method & 29,43 & \\
\hline
\end{tabular}


rates were higher than chance, except for 2 individuals (classification rates of $0 \%$ ). All individuals selected for the scream analysis were from cave 1 only, and thus the difference among individuals cannot be explained by a difference in the acoustic properties of the caves.

\section{DISCUSSION}

\section{Vocal repertoire}

Most of the vocalizations described in this study (i.e. screams, barks and chirps) were also described in the previous study by Muñoz et al. (2011), on both wild and rehabilitated Mediterranean monk seals. However, the squawks and gaggles produced by rehabilitated pups were not found in wild pups (Muñoz et al. 2011, this study). The new call type described in this study is the short scream, a vocalization produced in the same behavioural context (i.e. agonistic interactions) as screams, and sharing the same general characteristics (i.e. high-pitched vocalization with most of the energy below $1500 \mathrm{~Hz}$ ). The grunt is also a new call type not previously described, but due to a low sample size ( $\mathrm{n}=14)$, further research is needed to present a clear description of this call type. The 4 call types can be easily distinguished by their acoustical characteristics, especially their spectral features (LD1) and duration (LD2) (Fig. 2), but also by the context of production and the emitter. Indeed, pups produced only barks, whereas adults and juveniles produced screams, short screams and chirps. Barks are highly distinguishable from the other 3 call types by their spectral characteristics, as barks are lower pitched calls (E1500 > 44\%). Screams can be distinguished from short screams and chirps by their total duration.

We did not find a call type produced exclusively by adult males that could be linked to their breeding activity. It is likely that males produce underwater territorial calls, as mating occurs in the water. By producing underwater territorial calls, males advertise their presence to rivals and/or potential mates, and such a vocal display could limit the access of rivals to females, since most pupping caves are accessible only from the sea. In the closely related species, the Hawaiian monk seal, males have been observed to produce 2 types of underwater calls (i.e. foghorn calls and barks; Stirling \& Thomas 2003), but further research is still necessary for a clear understanding of their underwater vocal repertoire.

\section{Individual vocal signatures and monitoring}

The results of our study indicate that barks and screams are individually specific, and may therefore allow for good discrimination among individuals. Indeed, the DFAs show average classification rates higher than chance, with classification rates of 54.2 and $66.2 \%$ for barks and screams respectively $(34.7$ and $53.5 \%$ for cross-validated DFA).

The correct classification rates for barks and screams are within the range of rates measured for other phocid species, and even higher than those found in Weddell Leptonychotes weddellii, harbour Phoca vitulina, grey Halichoerus grypus, harp Pagophilus groenlandicus and Hawaiian monk seals (Table 4). Since in most of the aforementioned studies, barks are produced during affiliative social interactions, information on the individual identity can be very important for the receivers, especially in the context of mother-pup communication. Here, we found that barks produced by females and pups are individualized, and therefore could be involved in mother-pup recognition, thus facilitating reunions when females return from foraging. Allo-nursing and fostering seem to be common in Mediterranean monk seals (Karamanlidis et al. 2016), so this behaviour cannot be explained by a lack of individuality in their vocalizations, but may be a lack of vocal discrimination abilities, as found in the Hawaian monk seal (Job et al. 1995). Screams are mainly produced during agonistic interactions, so signalling individual identity might not be essential for both receivers and emitters. Such information could be used, however, to facilitate cooperation among individuals. In fact, screams can be interpreted as alarm or distress calls, so they may elicit cooperative and defensive behaviours from conspecifics and/or related individuals. Indeed, if a receiver (i.e. a conspecific) can assess the individual identity of the emitter from its screams, then it can adapt its behaviour and thus defend the vocalizing individual that is in danger or in a difficult situation. In contrast, there might be no selection on emitters to produce individualized calls (Blumstein \& Munos 2005), and individuality found in screams may only result from individual differences in their vocal apparatus (Fitch \& Hauser 1995).

Our findings on the individuality of barks and screams lead to the conclusion that these 2 call types could be used in the long-term passive acoustic monitoring of the Mediterranean monk seal. The classification rates recorded in the present study should be 
improved even more before passive acoustics can be used in the effective monitoring of this species. Future research should focus on the collection of additional recordings from new and well-identified individuals (individual identity, age- and sex-class) that will enable inclusion in the statistical analysis of new acoustic features, such as frequency modulation (FM) characteristics, as both call types exhibit a FM pattern. Following the collection of additional recordings, one could then test different machine learning algorithms for the automatic classification of vocalization (e.g. artificial neural network [ANN], $k$ nearest neighbors [k-NN], random forest classifier; Stowell \& Plumbley 2014, Turesson et al. 2016) in order to find the most reliable classification method for the long-term acoustic monitoring of the Mediterranean monk seal. The ongoing development of the automatic classification of animal vocalizations has proven its efficacy (Mielke \& Zuberbühler 2013, Stowell \& Plumbley 2014) and has opened new perspectives/opportunities in developing powerful tools to monitor animal biodiversity.

\section{Research and management implications and priorities}

Mediterranean monk seals in Greece have recently shown encouraging signs of population recovery (Karamanlidis et al. 2016), a fact that poses new challenges for the research and management of the species in the country. If the results of this study, combined with further research, enable the unequivocal identification of individual seals, then passive acoustic monitoring could help overcome some of the common limitations encountered with the traditional methods used to monitor the species and would prove to be, on its own and/or in combination with other methodologies, a powerful tool in the effective monitoring and conservation of the Mediterranean monk seal.

For a long time, traditional monitoring of the Mediterranean monk seal in the eastern Mediterranean Sea has relied on visiting the numerous marine caves frequented by the species and carrying out observations, which have been limited by the inaccessibility of the habitat and the shy nature of the species. Recently, monitoring success was greatly improved through the development and application of autonomous monitoring systems (Dendrinos et al. 2007b, Gücü 2009, Karamanlidis et al. 2010). However, even this development has proven to have certain limitations. Due to the geomorphology of the marine caves occupied by Mediterranean monk seals it is often impossible to cover the beach section of the cave that is frequented by the seals with a single or even multiple cameras; thus, some individuals visiting these caves might go undetected. Therefore, it is often necessary to combine the use of autonomous cameras with field observations in order to collect the necessary data for effective monitoring of the species. In addition, Mediterranean monk seals in Greece use a large number of caves for resting and pupping (Dendrinos et al. 2007a); however, for logistic reasons only a small number of these caves (i.e. usually the most important pupping sites) can be monitored using autonomous monitoring systems in combination with direct field visits.

These limitations have made it almost impossible, until now, to measure annual monk seal pup production - a fundamental population parameterthroughout Greece, and thus obtain a concrete picture of the reproductive and conservation status of the species in the country. These methodological limitations could be overcome by the development of a passive acoustic monitoring system that could be placed at a suitable spot in a marine cave (i.e. no need to have visual contact with the resting beach of the cave) to record a unique, individual vocal signature that would enable individual identification. Individual vocal signatures have been shown to be stable over time (i.e. northern elephant seals Mirounga angustirostris, Casey et al. 2015; primates, Symmes et al. 1979; hyenas Crocuta crocuta, East \& Hofer 1991) and have been used successfully in the monitoring and size estimation of wildlife populations (e.g. wild dogs Lycaon pictus, Hartwig 2005). In the particular case of monitoring Mediterranean monk seals in Greece, the assignment of a unique acoustic tag to a newborn pup would enable estimation of the annual pupping rate, which is considered the most important monitoring parameter for the conservation of the species in the country. Thus, acoustic tags would be similar to the genetic tags and photo-identification catalogues already used to monitor endangered species (Schwartz et al. 2007), without the need to handle individuals. Consequently, the deployment of passive acoustic monitoring equipment in all the important pupping/resting caves for the Mediterranean monk seal in Greece could be used in population monitoring of the species in the following ways: (1) in individual monitoring of the species (i.e. monitoring different individuals over multiple years), and (2) in estimation of a minimum population size through identification of different individuals and estimation of annual pup production. 
In the first case, individual acoustic monitoring (both under- and above-water) would provide baseline information on breeding behaviour and site fidelity, which in turn would inform spatial and marine protected area planning for the species. In the latter case, the development of an effective population assessment method would be of utmost importance for the conservation of the species, especially in the eastern Mediterranean Sea, where accurate population estimates are still missing for several areas (Karamanlidis \& Dendrinos 2015).

Finally, research on the vocal repertoire of the Endangered Mediterranean monk seal should also focus on underwater acoustic monitoring that will allow us not only to describe the vocal repertoire of the species and better understand its behaviour (e.g. underwater vocal activity during the breeding season), but also enable a better estimation of the seals' sonic environment: we would be able to assess the level of noise pollution near pupping/resting caves and determine whether Mediterranean monk seals alter their (vocal) behaviour when facing such noise disturbance. Such findings would have direct management implications by limiting human activities in the proximity of important resting/pupping areas.

Monitoring Mediterranean monk seals in Greece is technically and logistically difficult because unlike other seal species, when on land, Mediterranean monk seals occupy remote and inaccessible marine caves instead of open beaches (Dendrinos et al. 2007a). This difficulty is compounded by the fact that Greece has more than $16000 \mathrm{~km}$ of coastline, most of which is potential Mediterranean monk seal habitat. Over the years, traditional monitoring techniques such as visual observations and remote camera techniques have provided important baseline information that has shaped current conservation strategies. On the other hand, however, these techniques have their limitations and leave several questions on the status of the species unanswered. The development, therefore, of a new technique for monitoring Mediterranean monk seals based on acoustics will be of utmost importance for the effective conservation of this endangered species.

Acknowledgements. We thank Marianna Psaradellis for her assistance in the field work. This study was conducted in accordance with the guidelines of the research permits (92705/770/09-03-05 and 86286/340/31-01-07) issued by the Hellenic Ministry of Rural Development and Food. Financial support was provided in Greece partially by a research and conservation grant of the Marine Mammal Commission of the USA and The Mohamed bin Zayed Species Conservation Fund.

\section{LITERATURE CITED}

Blumstein DT, Munos O (2005) Individual, age and sex-specific information is contained in yellow-bellied marmot alarm calls. Anim Behav 69:353-361

Blumstein DT, Mennill DJ, Clemins P, Girod L and others (2011) Acoustic monitoring in terrestrial environments using microphone arrays: applications, technological considerations and prospectus. J Appl Ecol 48:758-767

Bradbury JW, Vehrencamp SL (1998) Principles of animal communication. Sinauer Associates, Sunderland, MA

* Briefer EF, Tettamanti F, McElligott AG (2015) Emotions in goats: mapping physiological, behavioural and vocal profiles. Anim Behav 99:131-143

Büyüköztürk Ş (2008) Discriminant function analysis: concept and application. Eur J Educ Res 33:73-92

* Casey C, Charrier I, Mathevon N, Reichmuth C (2015) Rival assessment among northern elephant seals: evidence of associative learning during male-male contests. R Soc Open Sci 2:150228

Charif RA, Clapham PJ, Clark CW (2001) Acoustic detections of singing humpback whales in deep waters off the British Isles. Mar Mamm Sci 17:751-768

Charrier I, Harcourt RG (2006) Individual vocal identity in mother and pup Australian sea lions (Neophoca cinerea). J Mammal 87:929-938

* Charrier I, Mathevon N, Jouventin P (2002) How does a fur seal mother recognize the voice of her pup? An experimental study of Arctocephalus tropicalis. J Exp Biol 205: 603-612

* Charrier I, Mathevon N, Jouventin P (2003) Individuality in the voice of fur seal females: an analysis study of the pup attraction call in Arctocephalus tropicalis. Mar Mamm Sci 19:161-172

* Charrier I, Aubin T, Mathevon N (2010) Mother-calf vocal communication in Atlantic walrus: a first field experimental study. Anim Cogn 13:471-482

Collins KT, Rogers TL, Terhune JM, McGreevy PD, Wheatley KE, Harcourt RG (2005) Individual variation of in-air female 'pup contact' calls in Weddell seals, Leptonychotes weddellii. Behaviour 142:167-189

* Collins KT, Terhune JM, Rogers TL, Wheatley KE, Harcourt RG (2006) Vocal individuality of in-air Weddell seal (Leptonychotes weddellii) pup 'primary' calls. Mar Mamm Sci 22:933-951

ํDendrinos P, Karamanlidis AA, Kotomatas S, Legakis A, Tounta E, Matthiopoulos J (2007a) Pupping habitat use in the Mediterranean monk seal: a long-term study. Mar Mamm Sci 23:615-628

* Dendrinos P, Tounta E, Karamanlidis AA, Legakis A, Kotomatas S (2007b) A video surveillance system for monitoring the endangered Mediterranean monk seal (Monachus monachus). Aquat Mamm 33:179-184

East ML, Hofer H (1991) Loud calling in a female-dominated mammalian society. 1. Structure and composition of whooping bouts of spotted hyaenas, Crocuta crocuta. Anim Behav 42:637-649

Fitch W, Hauser MD (1995) Vocal production in nonhuman primates: acoustics, physiology, and functional constraints on 'honest' advertisement. Am J Primatol 37: $191-219$

Gücü AC (2009) Preliminary study on the effects of photo traps used to monitor Mediterranean monk seals Monachus monachus. Endang Species Res 10:281-285

*Gwilliam J, Charrier I, Harcourt RG (2008) Vocal identity 
and species recognition in male Australian sea lions, Neophoca cinerea. J Exp Biol 211:2288-2295

*Hartwig S (2005) Individual acoustic identification as a noninvasive conservation tool: an approach to the conservation of the African wild dog Lycaon pictus (Temminck, 1820). Bioacoustics 15:35-50

Insley SJ (1992) Mother-offspring separation and acoustic stereotypy: a comparison of call morphology in two species of pinnipeds. Behaviour 120:103-122

Insley SJ, Phillips AV, Charrier I (2003) A review of social recognition in pinnipeds. Aquat Mamm 29:181-201

Job DA, Boness DJ, Francis JM (1995) Individual variation in nursing vocalizations of Hawaiian monk seal pups, Monachus schauinslandi (Phocidae, Pinnipedia), and lack of maternal recognition. Can J Zool 73:975-983

Karamanlidis AA, Dendrinos P (2015) Monachus monachus. The IUCN Red List of Threatened Species. 2015. e. T13653A45227543. http://dx.doi.org/10.2305/IUCN.UK. 2015-4.RLTS.T13653A45227543.en (accessed 15 December 2016)

Karamanlidis AA, Paravas V, Trillmich F, Dendrinos P (2010) First observations of parturition and postpartum behavior in the Mediterranean monk seal (Monachus monachus) in the Eastern Mediterranean. Aquat Mamm $36: 27-32$

Karamanlidis AA, Dendrinos D, Adamantopoulou S (2015) Discovery of an important monk seal colony at the island of Evia, Greece. In: Poulakakis N, Antoniou A, Karameta E, Psonis N (eds) $13^{\text {th }}$ International Congress on the Zoogeography and Ecology of Greece and Adjacent Regions. Hellenic Zoological Society, Irakleio

Karamanlidis AA, Dendrinos P, Fernández de Larrinoa P, Gücü AC, Johnson WM, Kiraç CO, Pires R (2016) The Mediterranean monk seal Monachus monachus: status, biology, threats, and conservation priorities. Mammal Rev 46:92-105

Khan CB, Markowitz H, McCowan B (2006) Vocal development in captive harbor seal pups, Phoca vitulina richardii: age, sex, and individual differences. J Acoust Soc Am 120:1684-1694

Klinck H, Mellinger DK, Klinck K, Hager J, Kindermann L, Boebel O (2010) Long-range underwater calls of the crabeater seal (Lobodon carcinophaga). J Acoust Soc Am 128:474-479

McCulloch S, Pomeroy PP, Slater PJB (1999) Individually distinctive pup vocalizations fail to prevent allo-suckling in grey seals. Can J Zool 77:716-723

Mellinger DK, Stafford KM, Moore S, Dziak RP, Matsumoto $\mathrm{H}$ (2007) Fixed passive acoustic observation methods for cetaceans. Oceanography 20:36-45

Mielke A, Zuberbühler K (2013) A method for automated individual, species and call type recognition in freeranging animals. Anim Behav 86:475-482

Moore SE, Stafford KM, Mellinger DK, Hildebrand JA (2006) Listening for large whales in offshore waters of Alaska. Bioscience 56:49-55

Mouy X, Hannay D, Zykov M, Martin B (2012) Tracking of Pacific walruses in the Chukchi Sea using a single hydrophone. J Acoust Soc Am 131:1349

* Muñoz G, Karamanlidis AA, Dendrinos P, Thomas JA (2011) Aerial vocalizations by wild and rehabilitating Mediterranean monk seals (Monachus monachus) in Greece. Aquat Mamm 37:262-279

Nieukirk SL, Stafford KM, Mellinger DK, Dziak RP, Fox CG (2004) Low-frequency whale and seismic airgun sounds recorded from the mid-Atlantic Ocean. J Acoust Soc Am 115:1832-1843

* Pitcher BJ, Harcourt RG, Charrier I (2012) Individual identity encoding and environmental constraints in vocal recognition of pups by Australian sea lion mothers. Anim Behav 83:681-690

R Development Core Team (2014) R: a language and environment for statistical computing. R Foundation for Statistical Computing, Vienna. http://www.R-project.org

* Risch D, Clark CW, Corkeron PJ, Elepfandt A and others (2007) Vocalizations of male bearded seals, Erignathus barbatus: classification and geographical variation. Anim Behav 73:747-762

Robisson P, Aubin T, Bremond JC (1993) Individuality in the voice of the emperor penguin Aptenodytes forsteri: adaptation to a noisy environment. Ethology 94:279-290

Rogers TL, Cato DH (2002) Individual variation in the acoustic behaviour of the adult male leopard seal, Hydrurga leptonyx. Behaviour 139:1267-1286

* Rogers TL, Ciaglia MB, Klinck H, Southwell C (2013) Density can be misleading for low-density species: benefits of passive acoustic monitoring. PLOS ONE 8:e52542

Samaranch R, González LM (2000) Changes in morphology with age in Mediterranean monk seals (Monachus monachus). Mar Mamm Sci 16:141-157

* Sauvé CC, Beauplet G, Hammill MO, Charrier I (2015) Acoustic analysis of airborne, underwater, and amphibious mother attraction calls by wild harbor seal pups (Phoca vitulina). J Mammal 96:591-602

* Scheel DM, Slater GJ, Kolokotronis SO, Potter CW and others (2014) Biogeography and taxonomy of extinct and endangered monk seals illuminated by ancient DNA and skull morphology. ZooKeys 409:1-33

Schwartz MK, Luikart GL, Waples RS (2007) Genetic monitoring as a promising tool for conservation and management. Trends Ecol Evol 22:25-33

พŠrović A, Hildebrand JA, Wiggins SM, McDonald MA, Moore SE, Thiele D (2004) Seasonality of blue and fin whale calls and the influence of sea ice in the Western Antarctic Peninsula. Deep-Sea Res II 51:2327-2344

Sokal RR, Rohlf FJ (1981) Biometry: the principles and practice of statistics in biological research. WH Freeman, New York, NY

* Stirling I, Thomas JA (2003) Relationships between underwater vocalizations and mating systems in phocid seals. Aquat Mamm 29:227-246

* Stowell D, Plumbley MD (2014) Automatic large-scale classification of bird sounds is strongly improved by unsupervised feature learning. PeerJ 2:e488

* Sueur J, Aubin T, Simonis C (2008) Equipment review: Seewave, a free modular tool for sound analysis and synthesis. Bioacoustics 18:213-226

* Symmes D, Newman JD, Talmage-Riggs G, Lieblich AK (1979) Individuality and stability of isolation peeps in squirrel monkeys. Anim Behav 27:1142-1152

* Thomas JA, DeMaster DP (1982) An acoustic technique for determining diurnal activities in leopard (Hydrurga leptonyx) and crabeater (Lobodon carcinophagus) seal. Can J Zool 60:2028-2031

*Titze IR (1994) Mechanical stress in phonation. J Voice 8: 99-105

Trimble M, Charrier I (2011) Individuality in South American sea lion (Otaria flavescens) mother-pup vocalizations: Implications of ecological constraints and geographical variations? Mamm Biol 76:208-216 
Turesson HK, Ribeiro S, Pereira DR, Papa JP, de Albuquerque VHC (2016) Machine learning algorithms for automatic classification of marmoset vocalizations. PLOS ONE 11:e0163041

Tyack P (1999) Communication and cognition. In: Reynolds III JE, Rommel SA (eds) Biology of marine mammals. Smithsonian Institution Press, Washington, DC, p 287-323

Van Opzeeland IC, Van Parijs SM (2004) Individuality in harp seal, Phoca groenlandica, pup vocalizations. Anim Behav 68:1115-1123

Van Opzeeland IC, Corkeron PJ, Risch D, Stenson G, Van Parijs SM (2009) Geographic variation in vocalizations of

Editorial responsibility: Simon Goldsworthy,

West Beach, South Australia, Australia pups and mother-pup behavior of harp seals Pagophilus groenlandicus. Aquat Biol 6:109-120

*Van Opzeeland I, Van Parijs SM, Bornemann H, Frickenhaus S, Kindermann L, Klinck H, Boebel O (2010) Acoustic ecology of Antarctic pinnipeds. Mar Ecol Prog Ser 414:267-291

*Van Parijs SM, Clark CW (2006) Long-term mating tactics in an aquatic-mating pinniped, the bearded seal, Erignathus barbatus. Anim Behav 72:1269-1277

* Watkins WA, Daher MA, Reppucci GM, George JE, Martin DL, DiMarzio NA, Gannon DP (2000) Seasonality and distribution of whale calls in the North Pacific. Oceanography 13:62-67

Submitted: August 3, 2016; Accepted: March 29, 2017 Proofs received from author(s): May 2, 2017 